\title{
Role of different immune cells and metabolic pathways in modulating the immune response in pancreatic cancer (Review)
}

\author{
NNENNA ELEBO, PASCALINE FRU, JONES OMOSHORO-JONES, \\ GEOFFREY PATRICK CANDY and EKENE EMMANUEL NWEKE \\ Department of Surgery, Faculty of Health Sciences, University of The Witwatersrand, \\ Johannesburg, Gauteng 2193, South Africa
}

Received May 21, 2020; Accepted September 16, 2020

DOI: $10.3892 / \mathrm{mmr} .2020 .11622$

\begin{abstract}
Pancreatic cancer is an aggressive cancer, making it a leading cause of cancer-related deaths. It is characteristically resistant to treatment, which results in low survival rates. In pancreatic cancer, immune cells undergo transitions that can inhibit or promote their functions, enabling treatment resistance and tumor progression. These transitions can be fostered by metabolic pathways that are dysregulated during tumorigenesis. The present review aimed to summarize the different immune cells and their roles in pancreatic cancer. The review also highlighted the individual metabolic pathways in pancreatic cancer and how they enable transitions in immune cells. Finally, the potential of targeting metabolic pathways for effective therapeutic strategies was considered.
\end{abstract}

\section{Contents}

1. Introduction

2. Role of immune cells in pancreatic cancer

3. Metabolic pathways and their influence on the immune response

Correspondence to: Dr Ekene Emmanuel Nweke, Department of Surgery, Faculty of Health Sciences, University of The Witwatersrand, 7 York Road Parktown, Johannesburg, Gauteng 2193, South Africa E-mail: ekene.nweke@wits.ac.za

Abbreviations: COX2, cyclooxygenase 2; DCs, dendritic cells; FAO, fatty acid oxidation; FAS, fatty acid synthesis; FASN, fatty acid synthetase; IDO, indoleamine-2.3-dioxygenase; LAT-1, L-type amino acid transporter; MDSCs, myeloid-derived suppressor cells; $\mathrm{NK}$, natural killer; $\mathrm{NKG}_{2} \mathrm{D}$, natural killer group 2 member; PDAC, pancreatic ductal adenocarcinoma; SHK, sedoheptulose kinase; T-eff, effector T cells; T-regs, regulatory $\mathrm{T}$ cells; TAMs, tumor-associated macrophages

Key words: pancreatic ductal adenocarcinoma, metabolic pathways, immune cells, metabolites, immune response
4. Recent treatment developments involving metabolic regulation

5. Conclusion and future perspectives

\section{Introduction}

Pancreatic cancer is the 7th most common cause of cancer-related deaths in developed countries and the 3rd most common in the USA, with $>250,000$ deaths worldwide annually (1). Pancreatic ductal adenocarcinoma (PDAC) is the most common type of pancreatic neoplasm and accounts for $>85 \%$ of pancreatic cancer cases globally (2). It originates in the head region of the pancreas and exhibits a glandular pattern, structurally similar to that of the ductal epithelial cells (3). Despite the high mortality rate in pancreatic cancer, the disease shows no early warning signs; therefore, pancreatic tumorigenesis and progression may remain undetected in a process that takes up to 20 years (4). The lack of early diagnostic markers has led to the delayed detection and late presentation of pancreatic cancer, which is usually at a locally advanced or metastatic stage at the time of diagnosis, thus making the disease fatal (5).

The immune system, which comprises the innate and the adaptive immune system, protects the host from foreign pathogens, including cancer cells (6). The innate immune system includes antigen-presenting cells, which phagocytose invading pathogens and present antigenic determinants with the major histocompatibility complex proteins (MHC)-II to $\mathrm{CD} 4^{+} \mathrm{T}$ cells. Granulocytes, mast cells, dendritic cells (DCs), macrophages and natural killers (NK) cells are also innate immune cells (7). The adaptive immune system is regulated and comprised mainly of $\mathrm{B}$ and $\mathrm{T}$ cells, which are usually activated when the innate immune system cannot eliminate the pathogens to provide long-lasting immunity (8).

The function and differentiation of immune cells are influenced by metabolism (Fig. 1) (9). Metabolism involves a series of chemical reactions that sustain life by converting food to energy and building blocks for larger compounds, such as proteins, lipids and nucleic acids (10). The chemical reactions involved in metabolism are structured into pathways. 
Metabolites are end-products of metabolism, which are generated by living organisms during their life cycles and could reflect the function of the organism (10).

\section{Role of immune cells in pancreatic cancer}

The dysfunctional immune system in pancreatic cancer has been discovered to promote tumor growth. The pancreatic cancer microenvironment was identified to serve a vital role in tumor growth and the therapeutic response (8). Pancreatic cancer cells are rich in stroma, which comprises both cellular and acellular components, including the extracellular matrix, fibroblasts, myofibroblasts, growth factors, cytokines, pancreatic stellate cells and immune cells (11). DCs, NK cells, CD8 ${ }^{+}$ and $\mathrm{CD}^{+} \mathrm{T}$ cells are some of the immune cells discovered to be activated to inhibit tumor growth and progression in PDAC $(12,13)$. Regulatory $\mathrm{T}$ cells (T-regs), tumor associated macrophages (TAM), myeloid-derived suppressor cells (MDSCs) and tumor-associated neutrophils have also been reported to promote tumor growth and progression, and also to suppress antitumoral responses $(8,11)$.

MDSCs suppress immunity by inhibiting $T$ cell activation via the sequestration of cysteine, thereby reducing the availability of the amino acids tryptophan and arginine, which are required for protein translation by $\mathrm{T}$ cells and reactive oxygen species (ROS) production (14). A previous study illustrated that the growth factor granulocyte-macrophage colony-stimulating factor, secreted by pancreatic tumors, promoted the early recruitment of MDSCs (15). MDSCs inhibit the immune functions of effector T (T-eff) cells and NK cells, while the function of T-regs is promoted $(16,17)$. Elevated MDSCs levels in pancreatic cancer were discovered to be a poor prognostic factor associated with elevated T-regs and Th2 cytokines levels (18). Using peripheral blood mononuclear cells harvested from blood samples collected from 131 patients with cancer, flow cytometric analysis revealed that both MDSC and T-reg levels were significantly elevated in patients with pancreatic cancer (18).

Macrophages switch their differentiation from M1 (proinflammatory) to M2 (anti-inflammatory) phenotypes in the presence of stimuli, such as the cytokines IL-10, IL-4, and TGF- $\beta$, which are secreted from the PDAC microenvironment $(19,20)$. TAMs are macrophages initially recruited to the site of tumor formation in response to the chemotactic factors released by pancreatic cancer cells, and they promote tumor progression by suppressing antitumor immune responses and stimulating the vascularization and metastasis of cancer cells (21). This has been demonstrated using immunohistochemistry to identify inflammatory cells by evaluating the expression of proangiogenic and prolymphangiogenic molecules, VEGFA and VEGFC, produced by macrophages in pancreatic cancer (22). Furthermore, TAMs were discovered to regulate pancreatic intraepithelial neoplasia progression by being the main source of IL- 6 in $\mathrm{Kras}^{\mathrm{G}}{ }^{\mathrm{I} 2 \mathrm{D}}$-mutations, thereby promoting cancer development (23). Elevated levels of TAMs and M2 polarized TAMs were also identified to be associated with a worse prognosis in pancreatic cancer by promoting lymphatic metastasis by lymphangiogenesis (20).

$\mathrm{CD}^{+} \mathrm{T}$ cells are affected in PDAC progression $(24,25)$. It has been shown that increased levels of $\mathrm{CD} 8^{+} \mathrm{T}$ cells led to favorable clinical outcomes and the improved survival of patients with PDAC (25). The effect of $\mathrm{CD}^{+} \mathrm{T}$ cells depends on their differentiation into their subtypes, Thelper cell type (Th)1, $\mathrm{Th} 2$ and Th17, and T-regs (26). CD8 ${ }^{+} \mathrm{T}$ cells are compromised in human pancreatic cancer due to the degradation of MHC-1 molecules by enhanced autophagy, which leads to immune evasion and the inhibition of antitumor activity $(24,27)$. Both cytotoxic and helper $T$ cells were found to be impaired by the influence of immunosuppressive cytokines, which promoted Th2 responses and led to tumor growth $(28,29)$. Immunohistochemical studies have demonstrated that the upregulation of $\mathrm{CD}^{+}$and $\mathrm{CD} 4^{+} \mathrm{T}$ cells predicted an improved prognosis in PDAC $(12,30)$. A decrease in the levels of T-eff cells was suggested to be associated with the progression from a premalignant to malignant stage in PDAC, because it was associated with reduced tumor growth $(24,31)$. In addition, elevated levels of Th1 cells contributed to a good clinical outcome because they produce IFN- $\gamma$ and TNF- $\alpha$, which promote anticancer activities by activating cytotoxic $\mathrm{T}$ cell responses, as well as antigen-presenting cells $(32,33)$.

The role of Th17 cells in pancreatic cancer is not completely understood because it depends on the cancer type, tumor stage and location (34). Previous studies have revealed that an increased level of Th17 cells in murine pancreatic cancer inhibited tumorigenesis, leading to improved survival (35), while in another study, elevated levels of Th17 cells in human pancreatic cancer promoted cancer progression and were associated with a poor survival $(36,37)$. Th2 cells exhibit a tumor-promoting function in pancreatic cancer, and this was suggested to be the result of the upregulated levels of Th2 cytokines, such as IL-13, IL-10 and IL-6, found in the plasma of patients with pancreatic cancer $(38,39)$. T-regs depend on oxidative phosphorylation and fatty acid oxidation (FAO) for ATP upon activation (40); this permits T-regs to survive under tumor conditions in contrast to T-eff cells, which are impaired due to insufficient glucose production (41). T-reg suppress immune responses via the secretion of IL-10 and TGF- $\beta$ to produce an immunosuppressive environment (42) and, in pancreatic cancer, they were discovered to be involved in the early infiltration of preinvasive lesions, promoting tumor growth and progression (31).

Cytotoxic lymphocyte-associated antigen-4 is a receptor found on T-regs that produces inhibitory signals upon interaction with its ligands, CD80 and CD86, on antigen-presenting cells, thereby inhibiting the formation of the immune synapse between $\mathrm{CD}^{+} \mathrm{T}$ cells and the antigen-presenting cells, which normally promotes the release of cytokines for cancer cell destruction (43). In patients with pancreatic cancer, a large number of T-regs in the circulation was associated with the advancement of the disease (44). The chances of successful surgical resection and survival rate post-resection were also discovered to be associated with the decreased levels of T-regs in patients with pancreatic cancer (44). Additionally, increased numbers of mast cells were identified to be associated with metastasis and reduced survival in human pancreatic cancer (45).

DCs control immune responses by regulating the polarization of T cells into Th1, Th2 or Th3 subtypes depending on the stimulation by certain cytokines (46). The pancreatic cancer microenvironment releases tumor-derived factors, 


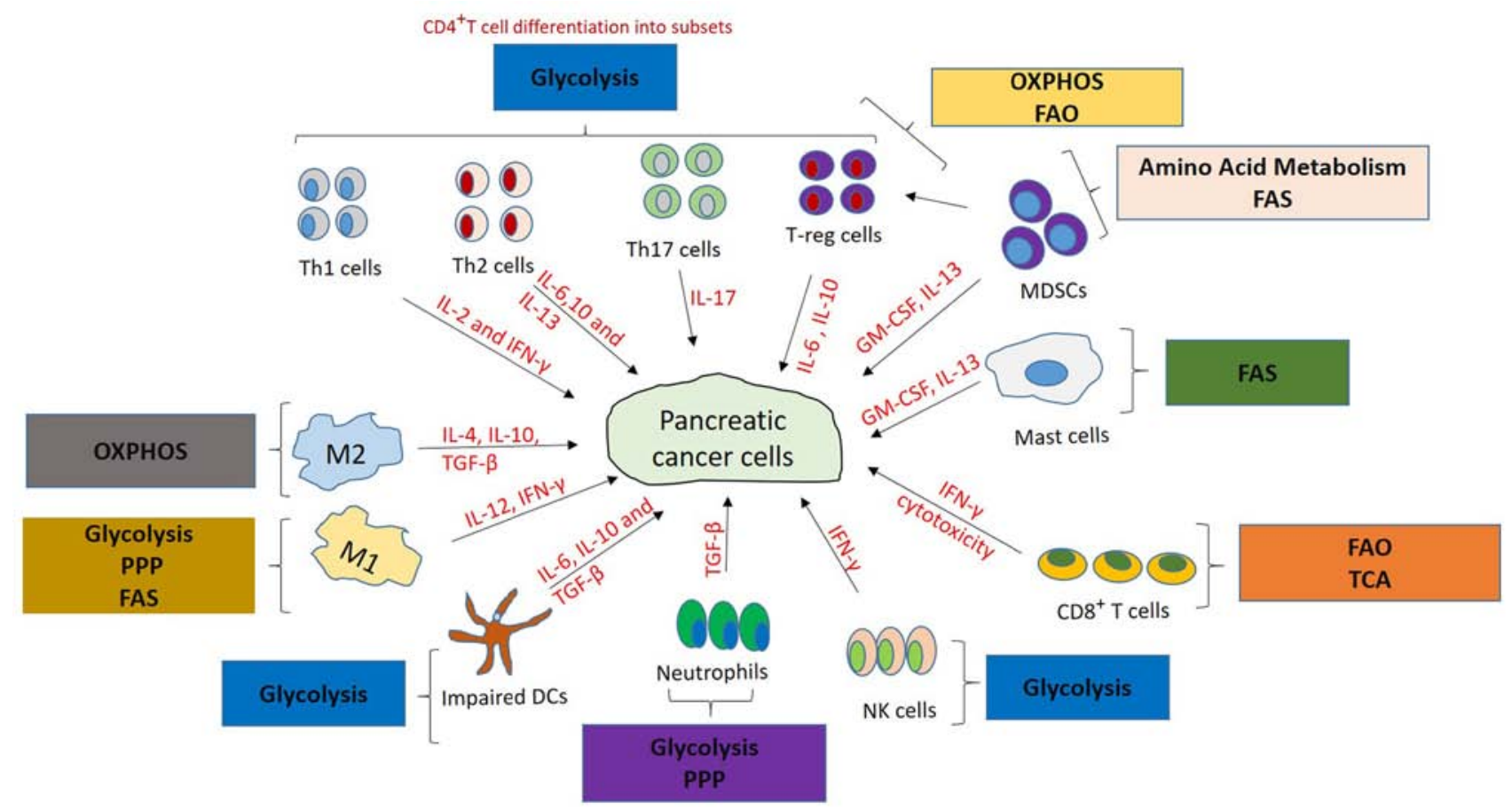

Figure 1. Interaction between the metabolic pathways and the immune cell network in pancreatic cancer. The immune network comprises the complex interactions between the innate immune cells, adaptive immune cells and the pancreatic cancer cells. Immunity in pancreatic cancer is greatly influenced by the chemokines and cytokines released by the tumor cells, such as IL- 6 and IL-10, as well as those released by the immune cells, such as IL-4, IL-13 and IFN- $\gamma$. Metabolic pathways also serve an important role in the reprogramming of these immune cells, either by activating, inhibiting or polarizing these immune cells. For instance, the switch from M1 to M2 macrophages is greatly influenced by FAO and the TCA cycle. Enhanced glycolysis is necessary for T cell differentiation into their subsets, Th1, Th2, Th17 and T-regs. Th1/2/17, T helper cell type 1/2/17; T-regs, regulatory T cells; MDSC, myeloid-derived suppressor cells; DCs, dendritic cells; FAO, fatty acid oxidation; GM-CSF, granulocyte-macrophage colony-stimulating factor; PDAC, pancreatic ductal adenocarcinoma; TCA, tricarboxylic acid; PPP, pentose phosphate pathway; NK, natural killer; FAS, fatty acid synthesis.

such as IL-6 and VEGF, which promote DC impairment by reprogramming the immune cell response from a Th1 type to a Th2 type, thereby promoting cancer development $(28,29)$. One previous study reported that the elevated levels of DCs and NK cells in PDAC were associated with a prolonged or improved survival rate (44).

The immune system uses NK cells to target cancer cells, which inhibits their growth, and a decreased level of NK cells was suggested to be associated with the advancement of pancreatic cancer. These findings were observed by determining the serum levels of soluble MHC class 1 chain-related molecule A (sMICA) and NK group 2-member $\mathrm{D}\left(\mathrm{NKG}_{2} \mathrm{D}\right)$ in the NK cells of patients with pancreatic cancer using immunohistochemistry. Elevated levels of sMICA were found in patients with advanced pancreatic cancer and were correlated with the downregulation of $\mathrm{NKG}_{2} \mathrm{D}$ expression, implying decreased levels of NK cells (47). Mast cells are commonly known for their role in allergies; however, in PDAC, elevated levels of mast cells were also discovered to be associated with tumor progression $(48,49)$.

\section{Metabolic pathways and their influence on the immune response}

The excessive growth of the extracellular matrix in pancreatic cancer as a result of the dense stroma was discovered to lead to the formation of barriers against the immune system, drug delivery, oxygen and nutrients (50). Hence, the cells develop mechanisms that alter the typical metabolic pathways to supply nutrients to survive (51). Immunotherapy promotes antitumor activities by reprogramming and enhancing the immune response $(34,52)$, and the function and differentiation of immune cells are greatly influenced by metabolism, hence a combination of both could be a more effective treatment option (53). Metabolic pathways can either promote or inhibit immune cell functions, which could be essential in further understanding the immune response and in identifying novel therapeutic options to treat immune-dysfunction in numerous types of disease, including cancer (Figs. 1 and 2).

Glycolysis. Glucose uptake and glycolysis are activated in pancreatic cancer cells, and their intermediates are fed into other biosynthetic pathways, such as the pentose phosphate pathway (PPP) (54). Glycolysis involves a series of enzymatic steps, whereby glucose is metabolized to pyruvate and then finally to lactate to yield ATP and other substrates for other metabolic pathways $(55,56)$. Glycolytic enzymes, such as hexokinase, enolase and phosphoglycerate kinase, among others, were found to be overexpressed in pancreatic cancer, promoting tumor growth and metastasis $(57,58)$. The expression of hypoxia-inducible genes in pancreatic cancer cell lines (MiaPaca-2 and Pcl-43) under different conditions was investigated, and hexokinase was identified to be upregulated (59). Glycolysis in pancreatic cancer was revealed to promote lactate production, tumor growth and protein glycosylation $(53,55,60)$. Although glycolysis is less energy efficient compared with the 


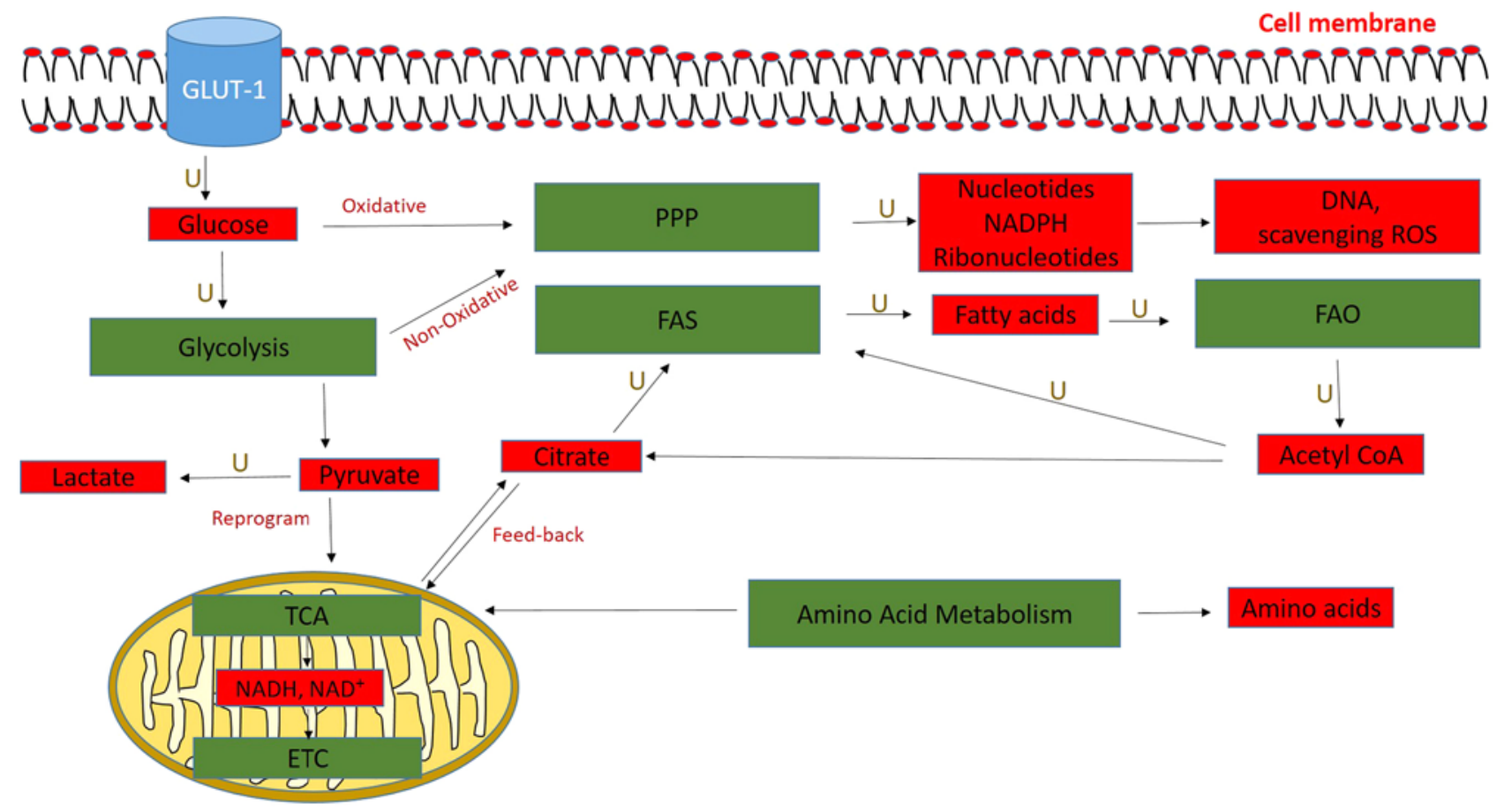

Figure 2. Metabolic pathways dysregulated in pancreatic cancer. The GLUT-1 transporter is upregulated in PDAC, which increases glucose uptake and glycolysis and promotes the flux of their intermediates into other metabolic pathways, such as the PPP. Glucose is metabolized into pyruvate, which feeds into the TCA cycle. Metabolic reprogramming of tumor cells restructures the TCA cycle and produces a high amount of lactate. The dysregulated FAS pathway contributes to the generation of building blocks for membrane synthesis. The fatty acids produced are oxidized via FAO to Acetyl CoA, which feeds back into the TCA cycle to generate NADH and NAD ${ }^{+}$and stimulates the electron transport chain to produce more ATP for the PDAC cells. In PDAC cells, both oxidative and non-oxidative phases of the PPP are upregulated to generate NADPH for scavenging ROS and nucleotides for DNA synthesis. Amino acid metabolism feeds into the TCA cycle to meet the high metabolic demands of the tumor cells. Red represents upregulated metabolites and green represents dysregulated metabolic pathways. PDAC, pancreatic ductal adenocarcinoma; GLUT-1, glucose transporter 1; PPP, pentose phosphate pathway; TCA, tricarboxylic acid; FAS, fatty acid synthesis; FAO, fatty acid oxidation; NADH, nicotinamide adenine dinucleotide; NADPH, nicotinamide adenine dinucleotide phosphate; ROS, reactive oxygen species; $\mathrm{U}$, upregulated.

tricarboxylic acid (TCA) cycle, it is preferred by cancer cells as it produces ATP faster, occurs independently of mitochondrial function and conserves nutrients for lipids, amino acids and nucleic acid biosynthesis (55). This phenomenon is known as the Warburg effect $(61,62)$ and, in PDAC, leads to increased lactate production, which alters the tumor stroma interface, thereby increasing invasiveness (63). Elevated lactic acid levels were identified to lead to a decreased $\mathrm{pH}$ in the tumor microenvironment, which inhibited cytotoxic $\mathrm{T}$ cell function and promoted tumor growth and progression (64).

M1 macrophages are characterized by enhanced glycolysis, while M2 macrophages exhibit decreased levels of glycolysis (65). M1-polarized macrophages are highly glycolytic due to the increased stimulation of the fructose-2,6-biphosphatase enzyme (66), which produces nitric oxide and TNF- $\alpha$ (67), and exhibit IL-12 and IL-23 phenotypes, while M2-polarised macrophages exhibit an IL-10 phenotype (19).

$\mathrm{T}$ cells require large amounts of glucose and glutamine catabolism for nucleotide and lipid synthesis, which are essential for cell growth. However, in their resting state (naïve state), they require small amounts of glucose, amino acids and fatty acids for the sustenance and maintenance of energy (68). Glycolysis is necessary for differentiating $\mathrm{CD}^{+} \mathrm{T}$ cells into its effector subsets, as well as maintaining a proper balance between protective and suppressive immunity (69). Glycolysis is essential for T-eff cell activation and function, because T-eff cells require high metabolic flux (70). T-eff cells are activated by the mTOR signaling pathway and hypoxia-inducible factor- $\alpha$ transcription factors, which promote glycolysis and amino acid metabolism, but uses FAO for ATP production (71). The mTOR signaling pathway is highly involved in metabolism, altering the expression of key pathways such as glycolysis $(72,73)$.

T-eff subsets, such as Th17, Th1 and Th2, require elevated levels of glycolysis following activation (69). Macintyre et al (40) demonstrated that glucose transporter (GLUT)-1 was essential for $\mathrm{CD} 4^{+} \mathrm{T}$ cell activation and effector function by examining the GLUT transporter family to determine their roles in glucose uptake and metabolism in $\mathrm{T}$ cells. The study also revealed that the levels of T-eff cells were elevated in GLUT-1 transgenic mice, which depend solely on glucose metabolism (69). Increased levels of glycolysis were also found to be required in order for activated B cells to contribute to the immune response (74). In addition, activated neutrophils were identified to depend on glucose for ATP production via glycolysis (75).

DCs are usually found in tissues that are in contact with external environment systems (76). They process and present antigens on the cell surfaces for T cells to respond to (77). In addition, DCs regulate the immune response by regulating the polarization of T cells to Th1, Th2 or Th3 subtypes following the stimulation by cytokines (46). Enhanced glycolysis occurs in DCs, which enables them to generate sufficient ATP and intermediates to perform the immune system functions. Krawczyk et al (78) demonstrated that DCs undergo 
maturation by Toll-like receptor signaling, and this occurred by the metabolic conversion from oxidative phosphorylation to aerobic glycolysis following the upregulation of fatty acid synthesis (FAS). The rapid induction of glycolysis was also discovered to be essential for the activation and function of DCs (79).

TCA cycle. The TCA cycle is a series of reactions that occur in the matrix of the mitochondria and involves the oxidation of Acetyl CoA to generate NADH and $\mathrm{FADH}_{2}$, which is then converted to ATP via the electron transport chain (Fig. 2) (80). The TCA cycle was discovered to be dysregulated in PDAC, in which increased levels of pyruvate from glycolysis were reduced to lactate and fed the TCA cycle to generate citrate for FAS (81). Metabolites such as fumarate, succinate and D2-hydroxyglutarate were reportedly upregulated in cancer cells as a result of the dysfunction of the enzymes, fumarate dehydrogenase, succinate dehydrogenase and isocitrate dehydrogenase (82). Elevated levels of these metabolites have been shown to increase ROS levels which, in turn, activated signaling pathways, such as P13K/AKT/mTOR, which promote carcinogenesis $(83,84)$. Macrophages are proinflammatory when there is a shift towards glycolysis and FAS, promoting the production of IL- $\beta$ and TGF- $\beta$. Conversely, macrophages are polarized towards the anti-inflammatory state when there is a shift towards the Krebs cycle and FAO (66). Increased citrate synthase activity was observed in PDAC upon measuring the activity in the tissues of patients with pancreatic cancer (85); citrate synthase catalyzes the reaction between Acetyl CoA and oxaloacetate to produce citrate, which is a substrate for membrane lipid synthesis (86). Although pancreatic cancer has been associated with elevated citrate synthase levels, increased citrate production inhibits phosphofructokinase (PFK)2 (87). PFK2 is a promoter of PFK1, an enzyme that catalyzes the conversion of fructose-6-phosphate to fructose-1,6-biphosphate in the presence of ATP, thereby controlling glycolysis in cancer cells. M2 macrophages, which are observed in PDAC, utilize oxidative phosphorylation to support their metabolic demands and have an uninterrupted Krebs cycle $(55,88)$.

$P P P$. The PPP consists of two phases, oxidative and non-oxidative, both of which were revealed to be upregulated in pancreatic cancer (86). The major products of the oxidative phase of PPP are nucleotides and NADPH, while the non-oxidative phase generates ribonucleotides for DNA synthesis, which is mediated by transketolase and transaldolase enzymes (89). The mRNA expression levels of transketolase were reported to be upregulated in the pancreatic cancer cell lines, Panc-1, MiaPaca-2 and CaPan-1 (90). In addition, a previous study revealed that the activation of the non-oxidative phase of the PPP in pancreatic cancer promoted resistance to gemcitabine treatment (91).

Macrophages are polarized towards an M2 phenotype when the PPP is inhibited, thus indicating the importance of the PPP in the pro- and anti-inflammatory response of macrophages, as shown in Fig. 1. Screening of 199 human kinases for their potential roles in immunoregulation revealed that the sedoheptulose kinase (SHK) enzyme, which limits the PPP, served an important role in macrophage polarization (92). In addition, the results proved that SHK enzyme downregulation was essential for the M1 reprogramming in macrophages. The PPP was found to be highly activated in lipopolysaccharide-activated macrophages due to the induction of the pyruvate kinase isoenzyme M2, which is an enzyme that diverts glycolytic intermediates to other biosynthetic pathways (93).

Amino acid metabolism.L-type amino acid transporter (LAT-1) transports large amino acids, such as tryptophan, valine, phenylalanine, tyrosine and histidine, among others (94). LAT-1 was discovered to be overexpressed in PDAC and was linked to angiogenesis and tumor cell proliferation (95). The breakdown of tissue proteins to branched-chained amino acids was revealed to be one of the early consequences of pancreatic cancer, thus, it may be used as a potential biomarker (96). For example, leucine, isoleucine and valine are branched-chain essential amino acids (97), which were reported to be elevated in pancreatic cancer because they are an alternative source of organic molecules that can fuel the TCA cycle. Exosomes derived from the tumor microenvironment were also identified to enhance the proliferation of pancreatic cancer cells by supplying metabolites, such as proteins, nucleic acids and amino acids $(54,98)$. Due to poor vascularization, pancreatic tumors do not have a sufficient supply of glutamine; instead, they use micropinocytosis to engulf extracellular proteins, which are subsequently degraded in lysosomes to release glutamine and other amino acids (99). PDAC is characterized by a low expression of glutamate dehydrogenase and the overexpression of glutamic oxaloacetic transaminase for the conversion of glutamine-derived aspartate to oxaloacetate in the cytoplasm, which is then further converted to malate and finally into pyruvate (100). Glutamine regulates the balance between T-eff cells and T-regs; however, in the PDAC microenvironment, the transporter protein, alanine-serine-cysteine transporter 2, was found to be deficient, leading to the diminished generation and function of Th17 and Th1 cells (101), hence promoting T-reg formation.

Upon activation, T cells consume a large amount of arginine and tryptophan to generate memory $\mathrm{T}$ cells by switching from glycolysis to oxidative phosphorylation, which activates antitumor activities (102). Amino acids produce derivatives that support cancer growth and progression; for example, in the PDAC microenvironment, the overexpression of indoleamine-2,3-dioxygenase (IDO) and arginase depleted tryptophan and arginine, thereby suppressing $\mathrm{T}$ cell proliferation and activating T-reg differentiation (103). Glutamate conversion into $\alpha$-ketoglutarate by glutamate dehydrogenase was discovered to promote cancer growth, because it served as an anaplerotic intermediate for the TCA cycle and provided nitrogen for non-essential amino acid biosynthesis (104).

\section{Lipid metabolism (FAO and FAS)}

$F A O$. FAO is an alternative source of Acetyl CoA that enters the TCA cycle for ATP production and energy (Fig. 2) (55). Pancreatic tumors and cell lines have been shown to overexpress the cyclooxygenase (COX)2 enzyme, which was identified to be associated with the invasiveness and metastasis of the disease (105). COX catalyzes the rate-limiting step in arachidonate metabolism to produce prostaglandin (106). The PDAC microenvironment was discovered to release endothelial growth factors, tumor promoters and cytokines, which 


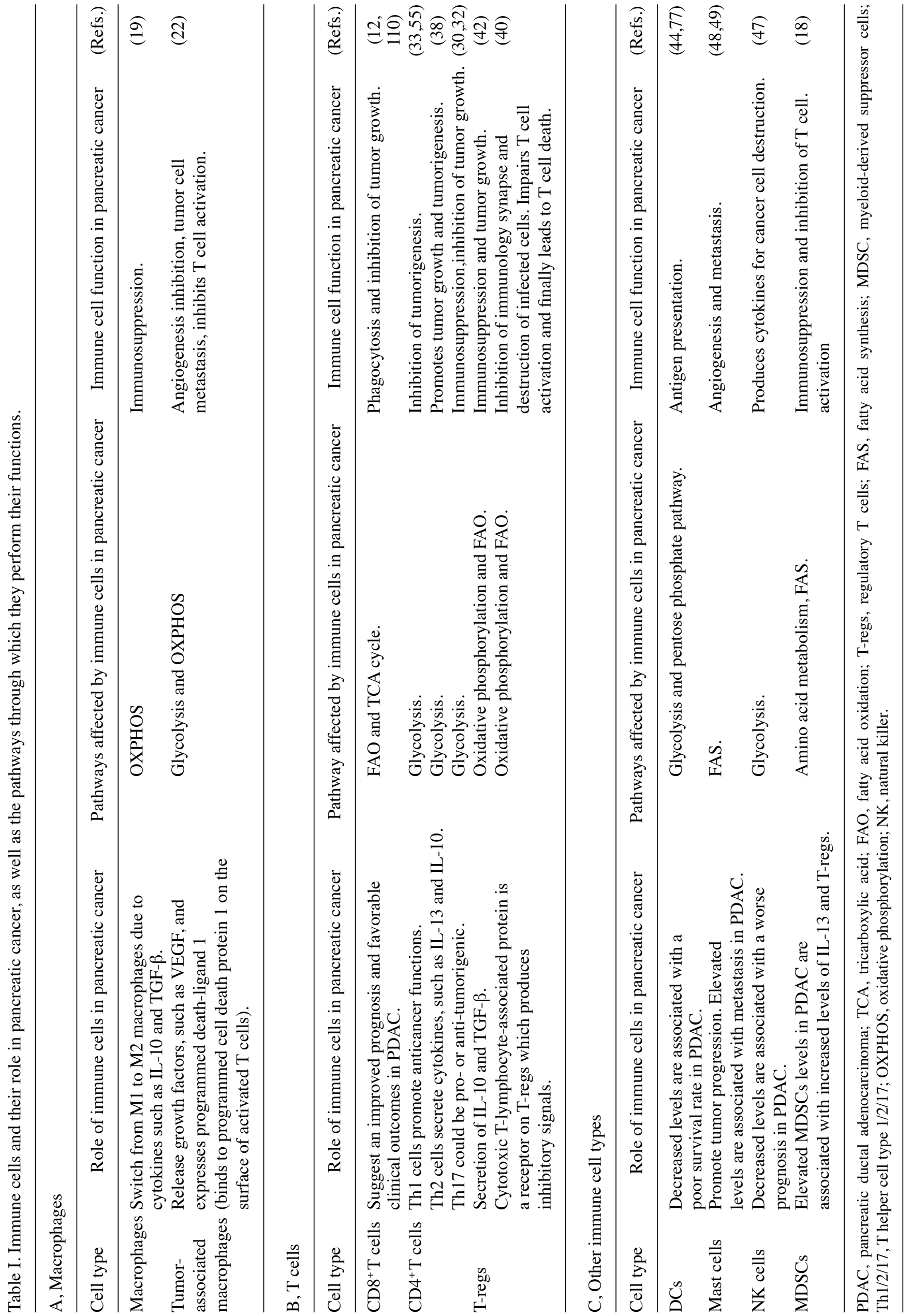


Table II. Metabolic pathways with potential roles as effective immunotherapeutic strategies.

\begin{tabular}{|c|c|c|}
\hline Metabolic pathway & Prospective immunotherapy strategies & (Refs.) \\
\hline \multirow[t]{6}{*}{ Glucose metabolism } & $\begin{array}{l}\text { Targeting the inhibition of tumor cell-derived lactate in human T cells, as this would } \\
\text { enhance T cell proliferation and the cytotoxic activities of } \mathrm{NK} \text { and } \mathrm{CD} 8^{+} \mathrm{T} \text { cells. }\end{array}$ & $(125)$ \\
\hline & Use of programmed cell death protein 1 blocking antibodies may promote antitumor & $(135)$ \\
\hline & activities by enhancing $\mathrm{T}$ cell proliferation via glycolysis inhibition and FAO promotion. & \\
\hline & Inhibition of key glycolytic enzymes, such as lactate dehydrogenase A and pyruvate & $(133,134)$ \\
\hline & kinase isoenzyme 2 is associated with the reduction of MDSCs infiltration and promote & \\
\hline & $\mathrm{CD}^{+} \mathrm{T}$ cells, $\mathrm{NK}$ and $\mathrm{T}$-eff cells. & \\
\hline \multirow[t]{2}{*}{ Lipid metabolism } & $\begin{array}{l}\text { Targeting the inhibition of cyclooxygenase } 2 \text { and the suppression of its metabolite } \\
\text { prostaglandin E2 using Paeonol to exert anticancer effects by inhibiting the } \\
\text { reprogramming from M1 to M2 macrophages. }\end{array}$ & $(129,132)$ \\
\hline & FAO inhibition in MDSCs to enhance T cell function and decrease cytokine production. & $(124,128)$ \\
\hline \multirow[t]{4}{*}{$\begin{array}{l}\text { Amino acid } \\
\text { metabolism }\end{array}$} & $\begin{array}{l}\text { Inhibition of indoleamine-2,3-dioxygenase to promote } \mathrm{T} \text { cell proliferation and response } \\
\text { to antigen presenting cells by secreting cytokines, which promote immunity. }\end{array}$ & $(136)$ \\
\hline & $\begin{array}{l}\text { Inhibition of glutamine metabolism using aminooxyacetate to mediate cytotoxicity in } \\
\text { tumor cells. }\end{array}$ & $(130)$ \\
\hline & $\begin{array}{l}\text { Targeting LAT- } 1 \text { and amino acid pathways using SM- } 88 \text { or anti-LAT- } 1 \text { antibodies to } \\
\text { promote tumor growth inhibition via disruption of protein synthesis and activation of } \\
\text { DCs and T cells. }\end{array}$ & $(95)$ \\
\hline & $\begin{array}{l}\text { Blockade of adenosine production by the inhibition of CD39 and CD73 to promote the } \\
\text { anticancer activity by activating DC maturation and T cells and NK cell activation. }\end{array}$ & $(123,126,131)$ \\
\hline
\end{tabular}

NK, natural killer; FAO, fatty acid oxidation; DC, dendritic cells; MDSCs, myeloid-derived suppressor cells; LAT-1, L-type amino acid transporter.

induced COX2 expression (107). Dubois et al (108) showed that transforming growth factor- $\alpha$ and tumor promoter tetradecanoyl phorbol acetate stimulate the production of eicosanoids, such as COX2, in rat intestinal epithelial cell culture. Increased expression of COX 2 plays a major role in the overproduction of prostaglandins $\mathrm{E}_{2}$, which inhibits immune response in malignant tissues (109). FAO was also indicated to serve an important role in regulating the balance between T-eff cells and suppressive T-regs, as it was observed to promote the generation of T-regs, while inhibiting T-eff cell polarization (69). FAO also enhanced the activation and maintenance of memory $\mathrm{CD}^{+} \mathrm{T}$ cells $(110)$.

FAS. Products derived from other cell metabolic pathways, such as glycolysis, the TCA cycle and PPP are used by cells to generate lipids for cellular growth in the FAS pathway (55). In pancreatic cancer, FAS involves the upregulation of ATP citrate lyase, Acetyl CoA carboxylase, fatty acid synthase (FASN), Acetyl CoA synthetase, stearoyl CoA desaturase, polyunsaturated fatty acids, monounsaturated fatty acids (MUFA) and saturated fatty acids (86). Some plasma lipids, such as very-low-density lipoproteins, were also discovered to be elevated, while low-density lipoprotein, high-density lipoprotein and 3-hydroxybutyrate were decreased in patients with PDAC (111). ATP-citrate lyase, an enzyme that converts citrate to Acetyl CoA which is a precursor for FAS, was also revealed to be upregulated in PDAC (112).

Deregulated FAS in PDAC, such as the biogenesis of fatty acids due to the overexpression of FASN, reportedly promoted cancer progression via resistance to chemotherapy (113).
Following resection, FASN levels are decreased in the majority of patients with PDAC, suggesting that elevated levels of FASN may be associated with a poor survival (114). Another enzyme that serves an essential role in FAS is acyl CoA synthetase, which converts long-chain fatty acids to acyl CoA, a critical step in phospholipid and triglycerol biosynthesis (115). Stearoyl-CoA desaturase-1 was demonstrated to exert an important role in the pathogenesis of PDAC by regulating the production of MUFAs (116). Alcohol and tobacco-related carcinomas, such as PDAC, have also been shown to overexpress the aldo-keto reductase family 1B10 (AKR1B10) enzyme, which catalyzes the production of aldehyde and NADPH from alcohol and $\mathrm{NADP}^{+}(117)$. AKR1B10 is essential in FAS by regulating the stability of Acetyl CoA carboxylase, which is able to catalyze the biosynthesis of malonyl CoA, a FASN substrate. Fatty acids are esterified to phospholipids, which are required for membrane formation, and this pathway was indicated to be the most abundant in advanced pancreatic cancer (86). Cholesterol uptake was also identified to be elevated in PDAC, as pancreatic cancer cells are highly dependent on cholesterol (118).

A summary of the discussed metabolic pathways and how they influence immune cells is presented in Table I.

\section{Recent treatment developments involving metabolic regulation}

Recent treatment developments involving TCA inhibition in PDAC include phase II and III clinical trials investigating a TCA cycle inhibitor devimistat, also known as CPI-613 ${ }^{\circledR}$ 
(ClinicalTrials.gov.nos. NCT03435289 and NCT03504423). The combination of CPI-613 with gemcitabine, nab paclitaxel and FOLFIRINOX have been explored for unresectable, locally advanced and metastatic PDAC $(119,120)$. In addition, the P13K-AKT-mTOR signaling pathway controls cell cycle, survival, metabolism and motility in cancer (121), therefore, studies targeting mTOR inhibition include phase I and II clinical trials (ClinicalTrials. gov.no. NCT03362412) investigating Sirolimus, an mTOR kinase inhibitor, for the treatment of patients with advanced pancreatic cancer (122). A combination of metabolic regulation and chemotherapy could be more effective than the use of chemotherapy alone.

\section{Conclusion and future perspectives}

The aggressive and unresponsive nature of pancreatic cancer highlights a requirement for an improved understanding of the mechanism of progression to provide effective therapeutic targets. Immunotherapy is a growing and promising treatment strategy in cancer; however, in pancreatic cancer, it is clear that further studies are required to investigate the effectiveness. The dysregulated interaction between the immune system and metabolic pathways in pancreatic cancer could provide greater insight into this disease. Furthermore, understanding these interactions may enable the development of effective therapeutic options that might increase the survival rate of patients. Targeting these pathways to enhance or elicit an immune response would be beneficial. Several studies have investigated the potential of targeting metabolic pathways and the effect on immune response in carcinogenesis (123-137), which are summarized in Table II. Future studies to determine these effects in pancreatic cancer and discover new targets may prove favorable.

\section{Acknowledgements}

Not applicable.

\section{Funding}

This study was funded by a grant from the South African Medical Research Council, which was awarded to the Wits Common Epithelial Cancer Research group. GPC was funded by the Cancer Association of South Africa (CANSA).

\section{Availability of data and materials}

Not applicable.

\section{Authors' contributions}

NE and EEN conducted the literature search. NE, PF, JOJ, GPC and EEN drafted the manuscript and critically revised the manuscript. EEN conceptualized the review article. All authors read and approved the final manuscript.

\section{Ethics approval and consent to participate}

Not applicable.

\section{Patient consent for publication}

Not applicable.

\section{Competing interests}

The authors declare that they have no competing interests.

\section{References}

1. Rawla P, Sunkara T and Gaduputi V: Epidemiology of pancreatic cancer: Global trends, etiology and risk factors. World J Oncol 10: 10-27, 2019

2. Ryan DP, Hong TS and Bardeesy N: Pancreatic adenocarcinoma. N Engl J Med 371: 1039-1049, 2014.

3. Polireddy K and Chen Q: Cancer of the pancreas: Molecular pathways and current advancement in treatment. J Cancer 7: 1497-1514, 2016.

4. Yachida S, Jones S, Bozic I, Antal T, Leary R, Fu B, Kamiyama M, Hruban RH, Eshleman JR, Nowak MA, et al: Distant metastasis occurs late during the genetic evolution of pancreatic cancer. Nature 467: 1114-1147, 2010.

5. Sarantis P, Koustas E, Papadimitropoulou A, Papavassiliou AG and Karamouzis MV: Pancreatic ductal adenocarcinoma: Treatment hurdles, tumor microenvironment and immunotherapy. World J Gastrointest Oncol 12: 173-181, 2020.

6. Ghesquière $\mathrm{B}$, Wong $\mathrm{BW}$, Kuchnio $\mathrm{A}$ and Carmeliet P: Metabolism of stromal and immune cells in health and disease. Nature 511: 167-176, 2014.

7. Hato $T$ and Dagher PC: How the innate immune system senses trouble and causes trouble. Clin J Am Soc Nephrol 10: 1459-1469, 2015.

8. Inman KS, Francis AA and Murray NR: Complex role for the immune system in initiation and progression of pancreatic cancer. World J Gastroenterol 20: 11160-11181, 2014.

9. Pearce EL and Pearce EJ: Metabolic pathways in immune cell activation and quiescence. Immunity 38: 633-643, 2013.

10. Odegaard JI and Chawla A: The immune system as a sensor of the metabolic state. Immunity 38: 644-654, 2013.

11. von Ahrens D, Bhagat TD, Nagrath D, Maitra A and Verma A: The role of stromal cancer-associated fibroblasts in pancreatic cancer. J Hematol Oncol 10: 76, 2017.

12. Fukunaga A, Miyamoto M, Cho Y, Murakami S, Kawarada Y, Oshikiri T, Kato K, Kurokawa T, Suzuoki M, Nakakubo Y, et al: $\mathrm{CD}^{+}$tumor-infiltrating lymphocytes together with $\mathrm{CD}^{+}$ tumor-infiltrating lymphocytes and dendritic cells improve the prognosis of patients with pancreatic adenocarcinoma. Pancreas 28: e26-e31, 2004.

13. Tjomsland V, Sandström P, Spångeus A, Messmer D, Emilsson J, Falkmer U, Falkmer S, Magnusson KE, Borch K and Larsson M: Pancreatic adenocarcinoma exerts systemic effects on the peripheral blood myeloid and plasmacytoid dendritic cells: An indicator of disease severity? BMC Cancer 10: 87, 2010.

14. De Sanctis F, Solito S, Ugel S, Molon B, Bronte V and Marigo I: MDSCs in cancer: Conceiving new prognostic and therapeutic targets. Biochim Biophys Acta 1865: 35-48, 2016.

15. Bayne LJ, Beatty GL, Jhala N, Clark CE, Rhim AD, Stanger BZ and Vonderheide RH: Tumor-derived granulocyte-macrophage colony-stimulating factor regulates myeloid inflammation and T cell immunity in pancreatic cancer. Cancer Cell 21: 822-835, 2012.

16. Padoan A, Plebani M and Basso D: Inflammation and pancreatic cancer: Focus on metabolism, cytokines, and immunity. Int J Mol Sci 20: 676, 2019.

17. Pergamo $\mathrm{M}$ and Miller G: Myeloid-derived suppressor cells and their role in pancreatic cancer. Cancer Gene Therapy 24: 100-105, 2017.

18. Gabitass RF, Annels NE, Stocken DD, Pandha HA and Middleton GW: Elevated myeloid-derived suppressor cells in pancreatic, esophageal and gastric cancer are an independent prognostic factor and are associated with significant elevation of the Th2 cytokine interleukin-13. Cancer Immunol Immunother 60: 1419-1430, 2011.

19. Dietl K, Renner K, Dettmer K, Timischl B, Eberhart K, Dorn C, Hellerbrand C, Kastenberger M, Kunz-Schughart LA, Oefner PJ, et al: Lactic acid and acidification inhibit TNF secretion and glycolysis of human monocytes. J Immunol 184: 1200-1209, 2010 
20. Kurahara H, Shinchi H, Mataki Y, Maemura K, Noma H, Kubo F, Sakoda M, Ueno S, Natsugoe S and Takao S: Significance of M2-polarized tumor-associated macrophage in pancreatic cancer. J Surg Res 167: e211-e219, 2011.

21. Mielgo A and Schmid MC: Impact of tumour associated macrophages in pancreatic cancer. BMB Rep 46: 131-138, 2013.

22. Esposito I, Menicagli M, Funel N, Bergmann F, Boggi U, Mosca F, Bevilacqua $\mathrm{G}$ and Campani D: Inflammatory cells contribute to the generation of an angiogenic phenotype in pancreatic ductal adenocarcinoma. J Clin Pathol 57: 630-636, 2004.

23. Lesina M, Kurkowski MU, Ludes K, Rose-John S, Treiber M Klöppel G, Yoshimura A, Reindl W, Sipos B, Akira S, et al: Stat3/Socs3 activation by IL-6 transsignaling promotes progression of pancreatic intraepithelial neoplasia and development of pancreatic cancer. Cancer Cell 19: 456-469, 2011.

24. Kim JS, Park YS, Kim JY, Kim YG, Kim YJ, Lee HK, Kim HS Hong JT, Kim Y and Han SB: Inhibition of human pancreatic tumor growth by cytokine-induced killer cells in nude mouse xenograft model. Immune Netw 12: 247-252, 2012.

25. Liu L, Zhao G, Wu W, Rong Y, Jin D, Wang D, Lou W and Qin X: Low intratumoral regulatory $\mathrm{T}$ cells and high peritumoral CD8(+) $\mathrm{T}$ cells relate to long-term survival in patients with pancreatic ductal adenocarcinoma after pancreatectomy. Cancer Immunol Immunother 65: 73-82, 2016

26. Kurts C: Th17 cells: A third subset of $\mathrm{CD} 4^{+} \mathrm{T}$ effector cells involved in organ-specific autoimmunity. Nephrol Dial Transplant 23: 816-819, 2007.

27. Yamamoto K, Venida A, Yano J, Biancur DE, Kakiuchi M, Gupta S, Sohn ASW, Mukhopadhyay S, Lin EY, Parker SJ, et al: Autophagy promotes immune evasion of pancreatic cancer by degrading MHC-I. Nature 581: 100-105, 2020.

28. Herber DL, Cao W, Nefedova Y, Novitskiy SV, Nagaraj S, Tyurin VA, Corzo A, Cho HI, Celis E, Lennox B, et al: Lipid accumulation and dendritic cell dysfunction in cancer. Nat Med 16: 880-886, 2010

29. Ochi A, Nguyen AH, Bedrosian AS, Mushlin HM, Zarbakhsh S, Barilla R, Zambirinis CP, Fallon NC, Rehman A, Pylayeva-Gupta Y, et al: MyD88 inhibition amplifies dendritic cell capacity to promote pancreatic carcinogenesis via $\mathrm{Th} 2$ cells J Exp Med 209: 1671-1687, 2012

30. Ino Y, Yamazaki-Itoh R, Shimada K, Iwasaki M, Kosuge T, Kanai $Y$ and Hiraoka N: Immune cell infiltration as an indicator of the immune microenvironment of pancreatic cancer. $\mathrm{Br}$ J Cancer 108: 914-923, 2013.

31. Hiraoka N, Onozato K, Kosuge T and Hirohashi S: Prevalence of $\mathrm{FOXP}^{+}$regulatory $\mathrm{T}$ cells increases during the progression of pancreatic ductal adenocarcinoma and its premalignant lesions. Clin Cancer Res 12: 5423-5434, 2006.

32. Knutson KL and Disis ML: Tumor antigen-specific $\mathrm{T}$ helper cells in cancer immunity and immunotherapy. Cancer Immunol Immunother 54: 721-728, 2005.

33. Wörmann SM, Diakopoulos KN, Lesina M and Algül H: The immune network in pancreatic cancer development and progression. Oncogene 33: 2956, 2013.

34. Zou W and Restifo NP: TH17 cells in tumour immunity and immunotherapy. Nat Rev Immunol 10: 248-256, 2010.

35. Gnerlich JL, Mitchem JB, Weir JS, Sankpal NV, Kashiwagi H, Belt BA, Porembka MR, Herndon JM, Eberlein TJ, Goedegebuure P and Linehan DC: Induction of Th17 cells in the tumor microenvironment improves survival in a murine model of pancreatic cancer. J Immunol 185: 4063-4071, 2010.

36. He Q, Luo X, Huang Y and Sheikh MS: Apo2L/TRAIL differentially modulates the apoptotic effects of sulindac and a COX-2 selective non-steroidal anti-inflammatory agent in Bax-deficient cells. Oncogene 21: 6032-6040, 2002.

37. He S, Fei M, Wu Y, Zheng D, Wan D, Wang L and Li D Distribution and clinical significance of Th17 cells in the tumor microenvironment and peripheral blood of pancreatic cancer patients. Int J Mol Sci 12: 7424-7437, 2011

38. De Monte L, Reni M, Tassi E, Clavenna D, Papa I, Recalde H, Braga M, Carlo VD, Doglioni C and Protti MP: Intratumor T helper type 2 cell infiltrate correlates with cancer-associated fibroblast thymic stromal lymphopoietin production and reduced survival in pancreatic cancer. J Exp Med 208: 469-478, 2011.

39. Bellone G, Turletti A, Artusio E, Mareschi K, Carbone A, Tibaudi D, Robecchi A, Emanuelli G and Rodeck U: Tumor-associated transforming growth factor- $\beta$ and interleukin-10 contribute to a systemic Th2 immune phenotype in pancreatic carcinoma patients. Am J Pathol 155: 537-547, 1999.
40. Macintyre AN, Gerriets VA, Nichols AG, Michalek RD, Rudolph MC, Deoliveira D, Anderson SM, Abel ED, Chen BJ, Hale LP and Rathmell JC: The glucose transporter Glut1 is selectively essential for CD4 T cell activation and effector function. Cell Metab 20: 61-72, 2014

41. Cham CM, Driessens G, O'Keefe JP and Gajewski TF: Glucose deprivation inhibits multiple key gene expression events and effector functions in CD8 ${ }^{+}$T cells. Eur J Immunol 38: 2438-2450, 2008.

42. Sakaguchi S, Miyara M, Costantino CM and Hafler DA: FOXP3 ${ }^{+}$ regulatory $\mathrm{T}$ cells in the human immune system. Nat Rev Immunol 10: 490-500, 2010.

43. Walker LS and Sansom DM: The emerging role of CTLA4 as a cell-extrinsic regulator of $\mathrm{T}$ cell responses. Nat Rev Immunol 11: 852-863, 2011

44. Yamamoto T, Yanagimoto H, Satoi S, Toyokawa H, Hirooka S, Yamaki S, Yui R, Yamao J, Kim S and Kwon AH: Circulating $\mathrm{CD} 4{ }^{+} \mathrm{CD} 25^{+}$regulatory $\mathrm{T}$ cells in patients with pancreatic cancer. Pancreas 41: 409-415, 2012

45. Chang DZ, Ma Y, Ji B, Wang H, Deng D, Liu Y, Abbruzzese JL, Liu YJ, Logsdon CD and Hwu P: Mast cells in tumor microenvironment promotes the in vivo growth of pancreatic ductal adenocarcinoma. Clin Cancer Res 17: 7015-7023, 2011.

46. Ito T, Amakawa R, Inaba M, Ikehara S, Inaba K and Fukuhara S: Differential regulation of human blood dendritic cell subsets by IFNs. J Immunol 166: 2961-2969, 2001.

47. Duan X, Deng L, Chen X, Lu Y, Zhang Q, Zhang K, Hu Y, Zeng J and Sun W: Clinical significance of the immunostimulatory MHC class I chain-related molecule A and NKG2D receptor on NK cells in pancreatic cancer. Med Oncol 28: 466-474, 2011.

48. Cai SW, Yang SZ, Gao J, Pan K, Chen JY, Wang YL, Wei LX and Dong JH: Prognostic significance of mast cell count following curative resection for pancreatic ductal adenocarcinoma. Surgery 149: 576-584, 2011

49. Strouch MJ, Cheon EC, Salabat MR, Krantz SB, Gounaris E, Melstrom LG, Dangi-Garimella S, Wang E, Munshi HG, Khazaie K and Bentrem DJ: Crosstalk between mast cells and pancreatic cancer cells contributes to pancreatic tumor progression. Clin Cancer Res 16: 2257-2265, 2010.

50. Feig C, Gopinathan A, Neesse A, Chan DS, Cook N and Tuveson DA: The pancreas cancer microenvironment. Clin Cancer Res 18: 4266-4276, 2012.

51. Stopa BK,Kusiak AA,Szopa DM,Ferdek EP and Jakubowska AM: Pancreatic cancer and its microenvironment-recent advances and current controversies. Int J Mol Sci 21: 3218, 2020

52. Li KY, Yuan JL, Trafton D, Wang JX, Niu N, Yuan CH, Liu XB and Zheng L: Pancreatic ductal adenocarcinoma immune microenvironment and immunotherapy prospects. Chronic Dis Transl Med 6: 6-17, 2020.

53. Li X, Wenes M, Romero P, Huang SC, Fendt SM and Ho PC: Navigating metabolic pathways to enhance antitumour immunity and immunotherapy. Nat Rev Clin Oncol 16: 425-441, 2019.

54. Yao W, Maitra A and Ying H: Recent insights into the biology of pancreatic cancer. EBioMedicine 53: 102655, 2020.

55. O'Neill LAJ, Kishton RJ and Rathmell J: A guide to immunometabolism for immunologists. Nat Rev Immunol 16: 553-565, 2016.

56. Palmer CS, Ostrowski M, Balderson B, Christian $\mathrm{N}$ and Crowe SM: Glucose metabolism regulates $\mathrm{T}$ cell activation, differentiation, and functions. Front Immunol 6: 1, 2015.

57. Chung JC, Oh MJ, Choi SH and Bae CD: Proteomic analysis to identify biomarker proteins in pancreatic ductal adenocarcinoma. ANZ J Surg 78: 245-251, 2008.

58. Yoon DY, Buchler P, Saarikoski ST, Hines OJ, Reber HA and Hankinson O: Identification of genes differentially induced by hypoxia in pancreatic cancer cells. Biochem Biophys Res Commun 288: 882-886, 2001.

59. Natsuizaka M, Ozasa M, Darmanin S, Miyamoto M, Kondo S, Kamada S, Shindoh M, Higashino F, Suhara W, Koide H, et al: Synergistic up-regulation of Hexokinase-2, glucose transporters and angiogenic factors in pancreatic cancer cells by glucose deprivation and hypoxia. Exp Cell Res 313: 3337-3348, 2007.

60. Cameron ME, Yakovenko A and Trevino JG: Glucose and lactate transport in pancreatic cancer: Glycolytic metabolism revisited. J Oncol 2018: 6214838, 2018

61. Vander Heiden MG, Cantley LC and Thompson CB: Understanding the Warburg effect: The metabolic requirements of cell proliferation. Science 324: 1029-1033, 2009.

62. Warburg O, Wind $\mathrm{F}$ and Negelein E: The metabolism of tumors in the body. J Gen Physiol 8: 519-530, 1927. 
63. Colegio OR, Chu NQ, Szabo AL, Chu T, Rhebergen AM, Jairam V, Cyrus N, Brokowski CE, Eisenbarth SC, Phillips GM, et al: Functional polarization of tumour-associated macrophages by tumour-derived lactic acid. Nature 513: 559-563, 2014.

64. Choi SYC, Collins CC, Gout PW and Wang Y: Cancer-generated lactic acid: A regulatory, immunosuppressive metabolite? J Pathol 230: 350-355, 2013.

65. Mills EL and O'Neill LA: Reprogramming mitochondrial metabolism in macrophages as an anti-inflammatory signal. Eur J Immunol 46: 13-21, 2016.

66. Rodríguez-Prados JC, Través PG, Cuenca J, Rico D, Aragonés J, Martín-Sanz P, Cascante M and Boscá L: Substrate fate in activated macrophages: A comparison between innate, classic, and alternative activation. J Immunol 185: 605-614, 2010.

67. Murray PJ, Allen JE, Biswas SK, Fisher EA, Gilroy DW, Goerdt S, Gordon S, Hamilton JA, Ivashkiv LB, Lawrence T, et al: Macrophage activation and polarization: Nomenclature and experimental guidelines. Immunity 41: 14-20, 2014.

68. Li Y and Zhu B: Editorial: Metabolism of cancer cells and immune cells in the tumor microenvironment. Front Immunol 9: 3080,2018

69. Michalek RD, Gerriets VA, Jacobs SR, Macintyre AN, MacIver NJ, Mason EF, Sullivan SA, Nichols AG and Rathmell JC: Cutting edge: Distinct glycolytic and lipid oxidative metabolic programs are essential for effector and regulatory $\mathrm{CD}^{+}{ }^{+} \mathrm{T}$ cell subsets. J Immunol 186: 3299-3303, 2011.

70. MacIver NJ, Michalek RD and Rathmell JC: Metabolic regulation of T lymphocytes. Annu Rev Immunol 31: 259-283, 2013.

71. Waickman AT and Powell JD: mTOR, metabolism, and the regulation of T-cell differentiation and function. Immunol Rev 249 43-58, 2012.

72. Mao Z and Zhang W: Role of mTOR in glucose and lipid metabolism. Int J Mol Sci 19: 2043, 2018.

73. Ersahin T, Tuncbag N and Cetin-Atalay R: The PI3K/AKT/mTOR interactive pathway. Mol Biosyst 11: 1946-1954, 2015.

74. Doughty CA, Bleiman BF, Wagner DJ, Dufort FJ, Mataraza JM Roberts MF and Chiles TC: Antigen receptor-mediated changes in glucose metabolism in B lymphocytes: Role of phosphatidylinositol 3-kinase signaling in the glycolytic control of growth Blood 107: 4458-4465, 2006.

75. Rodríguez-EspinosaO,Rojas-EspinosaO,Moreno-AltamiranoMMB López-Villegas EO and Sánchez-García FJ: Metabolic requirements for neutrophil extracellular traps formation. Immunology 145 213-224, 2015.

76. Dallal RM, Christakos P, Lee K, Egawa S, Son YI and Lotze MT: Paucity of dendritic cells in pancreatic cancer. Surgery 131 : $135-138,2002$.

77. Banchereau J and Steinman RM: Dendritic cells and the control of immunity. Nature 392: 245-252, 1998.

78. Krawczyk CM, Holowka T, Sun J, Blagih J, Amiel E, DeBerardinis RJ, Cross JR, Jung E, Thompson CB, Jones RG and Pearce EJ: Toll-like receptor-induced changes in glycolytic metabolism regulate dendritic cell activation. Blood 115: 4742-4749, 2010

79. Everts B, Amiel E, Huang SC, Smith AM, Chang CH, Lam WY, Redmann V, Freitas TC, Blagih J, van der Windt GJ, et al: TLR-driven early glycolytic reprogramming via the kinases TBK1-IKK $\varepsilon$ supports the anabolic demands of dendritic cell activation. Nat Immunol 15: 323-332, 2014.

80. Martínez-Reyes I and Chandel NS: Mitochondrial TCA cycle metabolites control physiology and disease. Nat Commun 11: $102,2020$.

81. Reyes-Castellanos G, Masoud R and Carrier A: Mitochondrial metabolism in PDAC: From better knowledge to new targeting strategies. Biomedicines 8: 270, 2020.

82. Laurenti G and Tennant DA: Isocitrate dehydrogenase (IDH), succinate dehydrogenase (SDH), fumarate hydratase $(\mathrm{FH})$ : Three players for one phenotype in cancer? Biochem Soc Trans 44: 1111-1116, 2016

83. Waitkus MS, Diplas BH and Yan H: Biological role and therapeutic potential of IDH mutations in cancer. Cancer Cell 34 186-195, 2018

84. Nogueira V and Hay N: Molecular pathways: Reactive oxygen species homeostasis in cancer cells and implications for cancer therapy. Clin Cancer Res 19: 4309-4314, 2013.

85. Schlichtholz B, Turyn J, Goyke E, Biernacki M, Jaskiewicz K, Sledzinski Z and Swierczynski J: Enhanced citrate synthase activity in human pancreatic cancer. Pancreas 30: 99-104, 2005.
86. Swierczynski J, Hebanowska A and Sledzinski T: Role of abnormal lipid metabolism in development, progression, diagnosis and therapy of pancreatic cancer. World J Gastroenterol 20 : 2279-2303, 2014.

87. Halabe Bucay A: Hypothesis proved...citric acid (citrate) does improve cancer: A case of a patient suffering from medullary thyroid cancer. Med Hypotheses 73: 271, 2009.

88. Amedei A, Niccolai E and Prisco D: Pancreatic cancer: Role of the immune system in cancer progression and vaccine-based immunotherapy. Hum Vaccin Immunother 10: 3354-3368, 2014

89. Patra KC and Hay N: The pentose phosphate pathway and cancer. Trends Biochem Sci 39: 347-354, 2014

90. Liu H, Huang D, McArthur DL, Boros LG, Nissen N and Heaney AP: Fructose induces transketolase flux to promote pancreatic cancer growth. Cancer Res 70: 6368-6376, 2010.

91. Shukla SK, Purohit V, Mehla K, Gunda V, Chaika NV, Vernucci E, King RJ, Abrego J, Goode GD, Dasgupta A, et al: MUC1 and HIF-1alpha signaling crosstalk induces anabolic glucose metabolism to impart gemcitabine resistance to pancreatic cancer. Cancer Cell 32: 71-87.e7, 2017.

92. Haschemi A, Kosma P, Gille L, Evans CR, Burant CF, Starkl P, Knapp B, Haas R, Schmid JA, Jandl C, et al: The sedoheptulose kinase CARKL directs macrophage polarization through control of glucose metabolism. Cell Metab 15: 813-826, 2012.

93. Palsson-McDermott EM, Curtis AM, Goel G, Lauterbach MA Sheedy FJ, Gleeson LE, van den Bosch MW, Quinn SR, Domingo-Fernandez R, Johnston DG, et al: Pyruvate kinase M2 regulates Hif- $1 \alpha$ activity and IL- $1 \beta$ induction and is a critical determinant of the warburg effect in LPS-activated macrophages. Cell Metab 21: 65-80, 2015.

94. Fernandez-Zapico M, Kim DW, Philip P, Vandell A, Eckard J, Korn R, Del Priore G and Simeone D: Abstract B15: Therapeutic potential of targeting amino acid metabolism in pancreatic cancer. Cancer Res 79: B15, 2019.

95. Altan B, Kaira K, Watanabe A, Kubo N, Bao P, Dolgormaa G, Bilguun EO, Araki K, Kanai Y, Yokobori T, et al: Relationship between LAT1 expression and resistance to chemotherapy in pancreatic ductal adenocarcinoma. Cancer Chemother Pharmacol 81: 141-153, 2018

96. Commisso C, Davidson SM, Soydaner-Azeloglu RG, Parker SJ, Kamphorst JJ, Hackett S, Grabocka E, Nofal M, Drebin JA, Thompson CB, et al: Macropinocytosis of protein is an amino acid supply route in Ras-transformed cells. Nature 497: 633-637, 2013.

97. Ananieva EA and Wilkinson AC: Branched-chain amino acid metabolism in cancer. Curr Opin Clin Nutr Metab Care 21: 64-70, 2018

98. Zhao H, Yang L, Baddour J, Achreja A, Bernard V, Moss T, Marini JC, Tudawe T, Seviour EG, San Lucas FA, et al: Tumor microenvironment derived exosomes pleiotropically modulate cancer cell metabolism. Elife 5: e10250, 2016.

99. Kamphorst JJ, Nofal M, Commisso C, Hackett SR, Lu W, Grabocka E, Vander Heiden MG, Miller G, Drebin JA, Bar-Sagi D, et al: Human pancreatic cancer tumors are nutrient poor and tumor cells actively scavenge extracellular protein. Cancer Res 75: 544-553, 2015.

100. Son J, Lyssiotis CA, Ying H, Wang X, Hua S, Ligorio M, Perera RM, Ferrone CR, Mullarky E, Shyh-Chang N, et al: Glutamine supports pancreatic cancer growth through a KRAS-regulated metabolic pathway. Nature 496: 101-105, 2013.

101. Singer K, Cheng WC, Kreutz M, Ho PC and Siska PJ: Immunometabolism in cancer at a glance. Dis Models Mech 11: dmm034272, 2018

102. Sinclair LV, Rolf J, Emslie E, Shi Y-B, Taylor PM and Cantrell DA: Control of amino-acid transport by antigen receptors coordinates the metabolic reprogramming essential for T cell differentiation. Nat Immunol 14: 500-508, 2013.

103. Pilotte L, Larrieu P, Stroobant V, Colau D, Dolusic E, Frédérick R, De Plaen E, Uyttenhove C, Wouters J, Masereel B and Van den Eynde BJ: Reversal of tumoral immune resistance by inhibition of tryptophan 2,3-dioxygenase. Proc Natl Acad Sci USA 109: 2497, 2012

104. Cluntun AA, Lukey MJ, Cerione RA and Locasale JW: Glutamine metabolism in cancer: Understanding the heterogeneity. Trends Cancer 3: 169-180, 2017.

105. Nzeako UC and Gores GJ: Increased expression of cyclooxygenase-2 in human pancreatic neoplasms and potential for chemoprevention by cyclooxygenase inhibitors. Cancer 94 : 1903-1904, 2002. 
106. Asano T,Shoda J,UedaT,Kawamoto T,Todoroki T,ShimonishiM, Tanabe T, Sugimoto Y, Ichikawa A, Mutoh M, et al: Expressions of cyclooxygenase-2 and prostaglandin E-receptors in carcinoma of the gallbladder: Crucial role of arachidonate metabolism in tumor growth and progression. Clin Cancer Res 8: 1157-1167, 2002.

107. Molina MA, Sitja-Arnau M, Lemoine MG, Frazier ML and Sinicrope FA: Increased cyclooxygenase- 2 expression in human pancreatic carcinomas and cell lines. Cancer Res 59: 4356-4362, 1999.

108. DuBois RN, Awad J, Morrow J, Roberts LJ II and Bishop PR: Regulation of eicosanoid production and mitogenesis in rat intestinal epithelial cells by transforming growth factor-alpha and phorbol ester. J Clin Invest 93: 493-498, 1994.

109. Sato T, Nakajima H, Fujio K and Mori Y: Enhancement of prostaglandin E2 production by epidermal growth factor requires the coordinate activation of cytosolic phospholipase A2 and cyclooxygenase 2 in human squamous carcinoma A431 cells. Prostaglandins 53: 355-369, 1997.

110. O'Sullivan D, van der Windt GJW, Huang SC, Curtis JD, Chang $\mathrm{CH}$, Buck MD, Qiu J, Smith AM, Lam WY, DiPlato LM, et al: Memory CD8(+) T cells use cell-intrinsic lipolysis to support the metabolic programming necessary for development. Immunity 41: 75-88, 2014.

111. Zhang A, Sun H, Wang P, Han Y and Wang X: Modern analytical techniques in metabolomics analysis. Analyst 137: 293-300, 2012.

112. Hatzivassiliou G, Zhao F, Bauer DE, Andreadis C, Shaw AN, Dhanak D, Hingorani SR, Tuveson DA and Thompson CB: ATP citrate lyase inhibition can suppress tumor cell growth. Cancer Cell 8: 311-321, 2005.

113. Tadros S, Shukla SK, King RJ, Gunda V, Vernucci E, Abrego J, Chaika NV, Yu F, Lazenby AJ, Berim L, et al: De novo lipid synthesis facilitates gemcitabine resistance through endoplasmic reticulum stress in pancreatic cancer. Cancer Res 77: 5503-5517, 2017.

114. Walter K, Hong SM, Nyhan S, Canto M, Fedarko N, Klein A, Griffith M, Omura N, Medghalchi S, Kuhajda F and Goggins M: Serum fatty acid synthase as a marker of pancreatic neoplasia. Cancer Epidemiol Biomarkers Prev 18: 2380-2385, 2009.

115. Coleman RA, Lewin TM, Van Horn CG and Gonzalez-Baró MR Do long-chain acyl-CoA synthetases regulate fatty acid entry into synthetic versus degradative pathways? J Nutr 132: 2123-2126, 2002

116. Macášek J, Vecka M, Žák A, Urbánek M, Krechler T, Petruželka L, Staňková B and Zeman M: Plasma fatty acid composition in patients with pancreatic cancer: Correlations to clinical parameters. Nutr Cancer 64: 946-955, 2012.

117. Chung YT, Matkowskyj KA, Li H, Bai H, Zhang W, Tsao MS, Liao J and Yang GY: Overexpression and oncogenic function of aldo-keto reductase family 1B10 (AKR1B10) in pancreatic carcinoma. Mod Pathol 25: 758-766, 2012.

118. Guillaumond F, Bidaut G, Ouaissi M, Servais S, Gouirand V, Olivares O, Lac S, Borge L, Roques J, Gayet O, et al: Cholesterol uptake disruption, in association with chemotherapy, is a promising combined metabolic therapy for pancreatic adenocarcinoma. Proc Natl Acad Sci USA 112: 2473-2478, 2015.

119. Alistar AT, Morris B, Harrison L, Bickenbach K, Starker L, Ginder N, McIlwain L, Luther S, Pardee TS and Alpert J: A single-arm, open-label, phase I study of CPI-613 (Devimistat) in combination with gemcitabine and nab-paclitaxel for patients with locally advanced or metastatic pancreatic adenocarcinoma. J Clin Oncol 38: 4635-4635, 2020.

120. Philip PA, Buyse ME, Alistar AT, Rocha Lima CMSP, Luther S, Pardee TS and Van Cutsem E: Avenger 500, a phase III open-label randomized trial of the combination of CPI-613 with modified FOLFIRINOX (mFFX) versus FOLFIRINOX (FFX) in patients with metastatic adenocarcinoma of the pancreas. J Clin Oncol 37: TPS479, 2019.
121. O'Donnell JS, Massi D, Teng MWL and Mandala M PI3K-AKT-mTOR inhibition in cancer immunotherapy, redux. Semin Cancer Biol 48: 91-103, 2018.

122. Jin $\mathrm{J}$ and Zhao Q: Emerging role of mTOR in tumor immune contexture: Impact on chemokine-related immune cells migration. Theranostics 10: 6231-6244, 2020.

123. Allard B, Longhi MS, Robson SC and Stagg J: The ectonucleotidases CD39 and CD73: Novel checkpoint inhibitor targets. Immunol Rev 276: 121-144, 2017.

124. Arina A and Bronte V: Myeloid-derived suppressor cell impact on endogenous and adoptively transferred T cells. Curr Opin Immunol 33: 120-125, 2015.

125. Brand A, Singer K, Koehl GE, Kolitzus M, Schoenhammer G, Thiel A, Matos C, Bruss C, Klobuch S, Peter K, et al: LDHA-associated lactic acid production blunts tumor immunosurveillance by T and NK cells. Cell Metab 24: 657-671, 2016.

126. Deaglio S, Dwyer KM, Gao W, Friedman D, Usheva A, Erat A, Chen JF, Enjyoji K, Linden J, Oukka M, et al: Adenosine generation catalyzed by CD39 and CD73 expressed on regulatory T cells mediates immune suppression. J Exp Med 204: 1257-1265, 2007.

127. Hiraoka N, Toue S, Okamoto C, Kikuchi S, Ino $\mathrm{Y}$, Yamazaki-Itoh R, Esaki M, Nara S, Kishi Y, Imaizumi A, et al: Tissue amino acid profiles are characteristic of tumor type, malignant phenotype, and tumor progression in pancreatic tumors. Sci Rep 9: 9816, 2019.

128. Hossain F, Al-Khami AA, Wyczechowska D, Hernandez C, Zheng L, Reiss K, Valle LD, Trillo-Tinoco J, Maj T, Zou W, et al: Inhibition of fatty acid oxidation modulates immunosuppressive functions of myeloid-derived suppressor cells and enhances cancer therapies. Cancer Immunol Res 3: 1236-1247, 2015.

129. Kalinski P: Regulation of immune responses by prostaglandin $\mathrm{E}_{2}$. J Immunol 188: 21-28, 2012.

130. Korangath P, Teo WW, Sadik H, Han L, Mori N, Huijts CM, Wildes F, Bharti S, Zhang Z, Santa-Maria CA, et al: Targeting glutamine metabolism in breast cancer with aminooxyacetate. Clin Cancer Res 21: 3263-3273, 2015.

131. Leone RD and Emens LA: Targeting adenosine for cancer immunotherapy. J Immunother Cancer 6: 57, 2018.

132. Li M, Tan SY and Wang XF: Paeonol exerts an anticancer effect on human colorectal cancer cells through inhibition of $\mathrm{PGE}_{2}$ synthesis and COX-2 expression. Oncol Rep 32: 2845-2853, 2014.

133. Liu WR, Tian MX, Yang LX, Lin YL, Jin L, Ding ZB, Shen YH, Peng YF, Gao DM, Zhou J, et al: PKM2 promotes metastasis by recruiting myeloid-derived suppressor cells and indicates poor prognosis for hepatocellular carcinoma. Oncotarget 6: 846-861, 2015 .

134. Mohammad GH, Olde Damink SW, Malago M, Dhar DK and Pereira SP: Pyruvate kinase M2 and lactate dehydrogenase A are overexpressed in pancreatic cancer and correlate with poor outcome. PLoS One 11: e0151635, 2016.

135. Patsoukis N, Bardhan K, Chatterjee P, Sari D, Liu B, Bell LN, Karoly ED, Freeman GJ, Petkova V, Seth P, et al: PD-1 alters T-cell metabolic reprogramming by inhibiting glycolysis and promoting lipolysis and fatty acid oxidation. Nat Commun 6: 6692, 2015.

136. Yu CP, Fu SF, Chen X, Ye J, Ye Y, Kong LD and Zhu Z: The clinicopathological and prognostic significance of IDO1 expression in human solid tumors: evidence from a systematic review and meta-analysis. Cell Physiol Biochem 49: 134-143, 2018.

137. Biswas SK: Metabolic reprogramming of immune cells in cancer progression. Immunity 43: 435-449, 2015.

This work is licensed under a Creative Commons Attribution-NonCommercial-NoDerivatives 4.0 International (CC BY-NC-ND 4.0) License. 